\title{
Self-reported oral health problems and the ability to organize dental care of community-dwelling elderly aged $\geq 75$ years
}

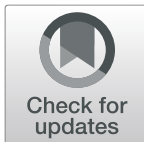

\author{
M. H. Bakker ${ }^{1 *}$ D, A. Vissink', S. L. W. Spoorenberg², K. Wynia ${ }^{2 \wedge}$ and A. Visser ${ }^{1,3}$
}

\begin{abstract}
Background: It is unclear how many community-dwelling elderly ( $\geq 75$ years) experience oral health problems (e.g. pain, dry mouth, chewing problems) and how they manage their dental care needs. This study aimed to assess selfreported oral health problems in elderly who are frail or have complex care needs, and their ability to organize dental care when reporting oral pain.

Methods: Three thousand five hundred thirty-three community-dwelling elderly participating in the "Embrace" project were asked to complete questionnaires regarding oral status and oral health problems. Frailty was assessed with the Groningen Frailty Indicator (GFI). Intermed for Elderly Self-Assessment (IM-E-SA) was used to determine complexity of care needs. Next, elderly who reported oral pain were interviewed about their oral pain complaints, their need for dental care, and their ability to organize and receive dental care. For statistical analyses $\mathrm{Chi}^{2}$-tests and the one-way ANOVA were used.
\end{abstract}

Results: One thousand six hundred twenty-two elderly (45.9\%) completed the questionnaires. Dry mouth (11.7\%) and oral pain (6.2\%) were most frequently reported. Among the elderly reporting oral pain, most were registered at a local dentist and could go there when needed (84.3\%). Robust elderly visited the dentist independently (87\%), frail (55.6\%) and complex (26.9\%) elderly more often required assistance from caregivers.

Conclusions: Dry mouth and oral pain are most reported oral health problems among community-dwelling elderly. Elderly with complex care needs report most oral health problems. In case an elderly seeks dental treatment to alleviate an oral pain complaint, most elderly in this study were able to organize dental care and transport to the dentist. Frail and complex elderly often need assistance from caregivers to visit the dentist. Therefore caretakers should keep in mind that when frailty progresses, visiting a dentist may become more and more difficult and the risk for poor oral health increases.

Keywords: Ageing, Oral health problems, Dental care use, Oral pain, Community-dwelling elderly

\footnotetext{
*Correspondence: m.h.bakker@umcg.nl

K. Wynia is deceased.

'Department of Maxillofacial Surgery, University of Groningen, University Medical Center Groningen, PO Box 30.001, NL-9700, RB, Groningen, The Netherlands

Full list of author information is available at the end of the article
}

(C) The Author(s). 2020 Open Access This article is licensed under a Creative Commons Attribution 4.0 International License, which permits use, sharing, adaptation, distribution and reproduction in any medium or format, as long as you give appropriate credit to the original author(s) and the source, provide a link to the Creative Commons licence, and indicate if changes were made. The images or other third party material in this article are included in the article's Creative Commons licence, unless indicated otherwise in a credit line to the material. If material is not included in the article's Creative Commons licence and your intended use is not permitted by statutory regulation or exceeds the permitted use, you will need to obtain permission directly from the copyright holder. To view a copy of this licence, visit http://creativecommons.org/licenses/by/4.0/. The Creative Commons Public Domain Dedication waiver (http://creativecommons.org/publicdomain/zero/1.0/) applies to the data made available in this article, unless otherwise stated in a credit line to the data. 


\section{Background}

Globally the population is growing and aging $[1,2]$. This development will have great impact on all healthcare systems. As people grow older, staying vital and healthy becomes challenging as elderly increasingly become frail and care-dependent [3]. Frailty is defined as a state in which older adults are vulnerable to sudden changes in health status because of a decline in physiological function and reserve [3]. Recent studies have shown that the prevalence of multimorbidity and polypharmacy rapidly increases with age, resulting in complex care needs in elderly $[4,5]$. Complex care needs may arise when elderly are suffering from multiple chronic diseases and polypharmacy and are treated by various medical healthcare professionals [6].

In the last two decades, as a result of improved dental care in the previous century, edentulism is decreasing and more and more elderly retain their own teeth until high age or receive dental implants [7]. Elderly with remaining teeth and elderly provided with dental implants to support their overdentures have a high risk of oral problems, especially when oral hygiene maintenance and dental visits become difficult due to frailty $[8,9]$. But even full dentures can become problematic when the denture fit is poor [8]. Frail and care-dependent elderly therefore have a relatively high risk of poor oral health and subsequently of oral pain (pain originating from oral tissues) [10]. This is a great hazard as poor oral health and oral pain have a negative effect on general health and quality of life, and can limit social interactions [11, 12].

Regular dental visits are therefore advised in order to prevent poor oral health. Research in the United States (US) has shown that only $46 \%$ of community-dwelling elderly visit the dentist for a general check-up, and this figure decreases as these elderly get older and subsequently become more frail [13]. When elderly can no longer live independently at home, they are often admitted in a nursing home. Studies showed that after dental examination $70 \%$ of the residents were in need of dental treatment $[14,15]$. Oral pain among communitydwelling elderly are described in literature [16-18]. For example, Hoeksema et al. [19] reported high a prevalence $(22 \%)$ of oral pain among community-dwelling elderly. However, the proportion of community-dwelling elderly who experience oral health problems such as dry mouth, oral pain and chewing problems and if these elderly are able to manage their dental care - especially when suffering from oral pain - remains unclear. Therefore, the aim of this study was to assess selfreported oral health problems (such as oral dryness, pain, chewing problems) in community-dwelling elderly (aged $\geq 75$ years) who are frail or have complex care needs. Next, it was assessed if and how these elderly are able to organize dental care when suffering from oral pain.

\section{Methods}

\section{Participants and study design}

We asked all community-dwelling elderly (aged $\geq 75$ years) living in the northern region of the Netherlands who were participating in the ongoing Embrace program for person-centered care to participate in our study [2023]. The Embrace program ("SamenOud" [aging together] in Dutch) focuses on elderly patients of general practitioners (GPs). Embrace is an integrated care service aimed to prolong the ability of older adults to age at home for as long as possible by providing comprehensive, coherent, person-centered, proactive, and preventive care and support. For an extensive description of the program see Spoorenberg et al. and Uittenbroek et al. [20-23].

The Medical Ethical Committee of the University Medical Center Groningen (the Netherlands) approved the Embrace study proposal (reference METc2011.108). Regarding the present study, they concluded that additional approval for assessing perceived oral health and the need for treatment was not required. The study was performed in accordance with the principles expressed in the Declaration of Helsinki.

\section{Procedures and assessments}

Between July 2017 and February 2018, a total of 3533 community-dwelling elderly participating in Embrace and living in the northern parts of the Netherlands received self-reporting questionnaires regarding demographics (age, sex, general health (underlying diseases, use of drugs)). In addition, oral status (remaining teeth (including fixed implant-retained structures), edentulous with a conventional denture or removable implantretained overdentures (IOD)), and oral health problems (oral pain, chewing problems, swallowing problems, dry mouth, feeling of insecurity regarding their oral status) experienced in the last 3 months were scored.

The elderly also completed a number of validated health-related questionnaires:

- Groningen Frailty Indicator (GFI): assesses physical and psychological frailty among elderly. This valid and reliable 15 -item instrument results in a score ranging from 0 to 15 , with higher scores corresponding with a higher level of frailty. A score of $\geq 4$ is regarded as frail [24].

- The INTERMED for the Elderly Self-Assessment (IME-SA): assesses the need for complex care of elderly. This valid and reliable instrument [6] consists of 20 questions in four domains (biological, psychological, social and healthcare), and it provides insight in perceived physical and cognitive abilities as well as healthcare needs. Scoring ranges from 0 to 60, with a higher score corresponding to a higher need for 
complex care. A cut-off value of $\geq 16$ was used to define elderly in need for complex care [6].

Elderly who completed all questionnaires were included in this study. Elderly with incomplete questionnaires were excluded from this study.

\section{Case complexity}

Participating elderly were categorized based on their IME-SA and GFI scores in three groups; 1) robust elderly, 2) frail elderly and 3) elderly with complex care needs. Robust elderly were defined as resilient persons in good health. Robust elderly showed low levels of frailty (GFI < 4) and a low level of complex care needs (IM-E-SA < 16). Frail elderly were defined as having a higher level of frailty $(\mathrm{GFI} \geq 4)$, but a low level of complex care needs (IM-E-SA < 16). Elderly with complex care needs were characterized by a high IM-E-SA score (IM-E-SA $\geq 16$ ).

\section{Interview on oral pain}

Elderly reporting oral pain were included for further research. Studies have shown that oral pain is a strong motivator to visit the dentist $[25,26]$, but it is unclear whether community-dwelling elderly are able to visit the dentist when they are suffering from oral pain. In this study researcher (MHB) contacted elderly with oral pain in the last 3 months by telephone for a structured interview. This was done within 2 weeks after the questionnaire had been returned. This interview was held to obtain additional information on the reported pain complaints and how these elderly organize their dental care needs. Information acquired by the interview:

- Actual status of reported oral pain;

- Severity of actual pain on a visual analog scale of 1 to 10 , where 10 indicates severe pain;

- Etiology of oral pain;

- History of oral pain;

- Location of oral pain;

- Medication and actions the participant had already taken regarding the reported oral pain (e.g., taking painkillers, visiting a dentist, using mouthwash, additional dental cleaning, consulting friends, visiting a general practitioner);

- Regular visits to the dentist;

- Transport to the dentist.

In case oral pain was still present and the dentist or a specialist had not been visited thus far, the research team advised the patient to visit a dentist. After the structured interview all participants received a letter containing a short summary of the interview including the given advice for organizing an appointment with the dentist.
If the oral pain complaint was complicated (e.g., burning mouth syndrome, pain related to previous head and neck oncology treatment) and the earlier consulted dentist could not alleviate the pain complaint, the patient was advised to return to the dentist and inform whether it would be possible to be referred to a maxillofacial surgeon. Elderly who were advised to visit a dentist or specialist were contacted again after 6-8 weeks. In this second interview, the participants were asked whether they had visited a dentist or maxillofacial surgeon and what the current status of their oral pain complaint was. Elderly were excluded when they did not give consent to the interview or when they could not be contacted or did not answer the telephone.

\section{Statistical analysis}

Data analysis was performed with IBM SPSS Statistics 23 (SPSS Inc., IBM Company, IBM Corporation, Chicago, IL, US). A significance level of $p<0.05$ was chosen for all tests. The Shapiro-Wilkins test was used to assess normality of the data $(\mathrm{p}<0.05)$. Median and interquartile ranges were provided for the not normally distributed clinical parameters. Mean and standard deviation were used for normally distributed parameters. $\mathrm{Chi}^{2}$ tests were used to assess significant differences between elderly with different risk profiles. For normally distributed variables one-way ANOVA was used, post hoc analysis was performed using independent-samples t-test. $P<$ 0.05 was determined as cut-off value. Because interviews were used to assess oral pain, no missing data were encountered.

\section{Results}

\section{Respondents}

Demographics of the respondents are shown in Table 1. Next, the flowchart of this study is shown in Fig. 1. All 3533 elderly who participated in Embrace were eligible and invited to join this study. In total, 1622 elderly (45.9\%) returned the questionnaires. Dry mouth (11.7\%) and oral pain $(6.2 \%)$ were most reported oral health problems. Elderly with complex care needs reported most frequently oral pain, dry mouth, swallowing problems, chewing problems and an insecure feeling. Elderly who reported oral pain $(n=100,6.2 \%)$ were telephoned within 2 weeks after the questionnaire had been returned and invited to participate in an additional structured interview, of which $89(89 \%)$ responded positively (8 elderly decided not to participate in the interview, and 3 elderly could not be contacted).

\section{First interview}

Of the 100 respondents reporting oral pain, 32.6\% $(n=$ 29 ) were still suffering from oral pain at the time of the interview, and $38.2 \%(n=34)$ reported that the pain had 
Table 1 Patient characteristics

\begin{tabular}{|c|c|c|c|c|c|}
\hline Patient characteristics $(n, \%)$ & $\begin{array}{l}\text { Total } \\
(n=1622)\end{array}$ & $\begin{array}{l}\text { Robust } \\
(n=1133)\end{array}$ & $\begin{array}{l}\text { Frail } \\
(n=226)\end{array}$ & $\begin{array}{l}\text { Complex } \\
(n=263)\end{array}$ & $P$-value between groups \\
\hline Female & $897(55.3 \%)$ & $597(52.7 \%)^{a}$ & $145(64.2 \%)$ & $155(58.9 \%)$ & 0.003 \\
\hline Age (mean, SD) & $82(4.4)$ & $82(4.5)^{a, b}$ & $83(3.9)$ & $82(4.1)$ & 0.023 \\
\hline \multicolumn{6}{|l|}{ Oral status } \\
\hline Edentulous & $722(44.5 \%)$ & $479(42.3 \%)^{b}$ & $100(44.2 \%)$ & $143(54.4 \%)$ & 0.002 \\
\hline Implant overdenture & $189(11.7 \%)$ & $131(11.6 \%)$ & 27 (11.9\%) & $31(11.8 \%)$ & 0.984 \\
\hline Remaining teeth & $711(43.8 \%)$ & $523(46.2 \%)^{\mathrm{b}}$ & 99 (43.8\%) & 89 (33.8\%) & 0.001 \\
\hline \multicolumn{6}{|l|}{ Oral health problems } \\
\hline Oral pain & $100(6.2 \%)$ & $58(5.1 \%)^{b}$ & $15(6.6 \%)$ & $27(10.3 \%)$ & 0.007 \\
\hline Chewing problems & $92(5.7 \%)$ & $52(4.6 \%)^{b}$ & $14(6.2 \%)$ & $26(9.9 \%)$ & 0.003 \\
\hline Swallowing problems & $36(2.2 \%)$ & $14(1.2 \%)^{b}$ & $6(2.7 \%)$ & $16(6.1 \%)$ & $<0.001$ \\
\hline Dry mouth & $190(11.7 \%)$ & $105(9.3 \%)^{a, b}$ & $34(15 \%)$ & $51(19.4 \%)$ & $<0.001$ \\
\hline Insecurity & $77(4.7 \%)$ & $41(3.6 \%)^{c}$ & $12(5.3 \%)$ & $24(9.1 \%)$ & 0.001 \\
\hline \multicolumn{6}{|c|}{ Total number of oral health problems } \\
\hline 1 problem & $288(17.8 \%)$ & $163(14.4 \%)^{a, b}$ & $56(24.8 \%)$ & $69(26.2 \%)$ & $<0.001$ \\
\hline 2 problems & $73(4.5 \%)$ & $38(3.4 \%)^{b}$ & $11(4.9 \%)$ & $24(9.1 \%)$ & $<0.001$ \\
\hline 3 problems & $17(1.0 \%)$ & $7(0.6 \%)^{b}$ & $1(0.4 \%)$ & $9(3.4 \%)$ & $<0.001$ \\
\hline 4 problems & - & - & - & - & - \\
\hline 5 problems & $2(0.1 \%)$ & $2(0.2 \%)$ & - & - & 0.386 \\
\hline
\end{tabular}

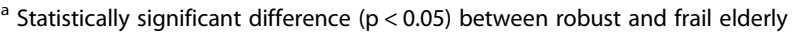

b Statistically significant difference $(p<0.05)$ between robust and complex elderly

or has lasted for over 6 weeks (Table 2). There were no statistically significant differences between respondents with different risk profiles. In order to relieve their oral pain, $56.2 \%$ of the elderly had already visited the dentist.

Among the participants $10.1 \%(n=9)$ could not remember their reported pain complaint and seemed to have no complaints anymore. The most frequently reported pain problems were toothache $(23.6 \%)$ and denture-related (fitting) complaints (24.7\%) (Table 2). Minor dental complaints, i.e. complaints that did not require painkillers or urgent dental treatment (such as sensitive teeth), were reported by $23.6 \%$ of the elderly. The type of complaints did not differ between respondents with different risk profiles. Most oral pain complaints were related to the lower jaw (43.8\%). Of all participants, 9.0\% stated their oral complaint was located throughout the oral cavity, no specific location could be determined.

Most elderly participants reported that they were registered at a local dentist (85.4\%) and had been visiting their local dentist within the last year (75.3\%) for regular dental care. They were often able to visit the dentist independently (70.8\%). Robust elderly were in most cases able to go to the dentist independently (87.0\%), in contrast to frail (44.4\%) and complex elderly $(46.2 \%)$, who required more assistance from caregivers $(p<0.001)$.
After the interview $21.4 \%$ of elderly with oral pain $(n=19)$ were advised to visit a local dentist and $2.2 \%$ were advised to return to their dentist and inform if they could be referred to specialist care $(n=2)$, as these elderly had been suffering from oral pain that could not be resolved by their local dentist (e.g. burning mouth problems). All elderly were contacted after 6-8 weeks for a follow-up interview.

\section{Follow-up interview}

The 21 elderly who were advised to visit a dentist or specialist were telephoned for a follow-up interview, of which 19 elderly could be contacted (Table 3). Most of these elderly ( $n=15,78.9 \%)$ had visited or has an upcoming appointment at their dentist or an oral and maxillofacial surgeon. Only 4 elderly had not visited their dentist. This was because they did not feel the need to visit the dentist and there were other urgent matters.

\section{Discussion}

The world population is aging and the number of individuals living in community-dwelling elderly has grown $[1,2]$. In addition, as a result of improved dental care, edentulism is decreasing and more elderly people are retaining their own teeth [7]. However, frail and caredependent elderly people are at high risk for oral health problems and pain [10]. Thus far it remains unclear how 


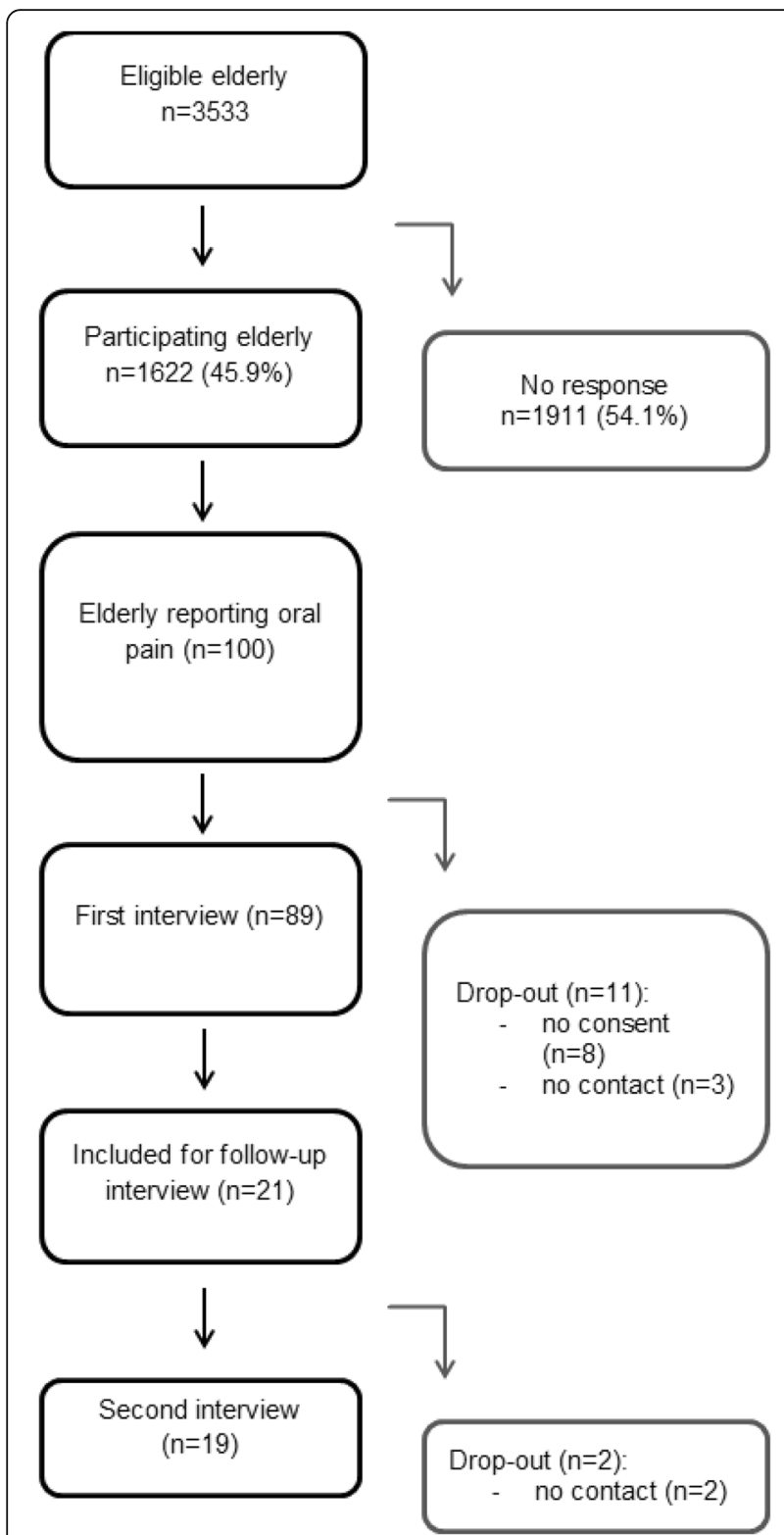

Fig. 1 Flow diagram of patient inclusion process

many community-dwelling experience oral health problems whether they are able to manage their dental care, especially when suffering from oral pain. This study showed that among community-dwelling elderly most reported oral health problems were dry mouth (11.7\%) and oral pain (6.2\%). Elderly with complex care needs report most frequently oral pain, dry mouth, chewing problems, swallowing problems and a feeling of insecurity. Frail and complex elderly often need assistance of caregivers to visit the dental office.

The prevalence of $6.2 \%$ elderly with oral pain differed substantially from the results of Hoeksema et al. [19], who reported a $22 \%$ prevalence of oral pain among a comparable group of elderly. The reason for this difference might be related to the difference in the evaluation period during which oral pain was experienced: in the study of Hoeksema et al., this period was 'during the last 2 years', [19] while in our study we asked about pain 'during the last 3 months'. Other studies have shown a prevalence of oral pain and/or oral discomfort at time of the questionnaire ranging from 5.4 to $33.6 \%$ among community-dwelling elderly $[17,27]$.

Another problem with the interpretation of the reported pain prevalence is that most studies do not report symptoms of the oral pain complaint. Only Gluzman et al. [17] provided insight into the symptoms of the complaint. Among their 125 medically-compromised and homebound elderly they found that $15.1 \%$ had toothache. This is comparable to the prevalence of toothache in our study (21.3\%) which was the second most frequently reported pain complaint, after denturerelated pain complaints (24.7\%).

Previous studies using these the same risk profiles (robust, frail and complex care needs) among communitydwelling elderly as has been used in our study show similar outcome: frail elderly and elderly with complex care needs show worse general (activities of daily living, quality of life) and oral health outcomes $[19,28]$ when compared to robust elderly. Other studies have shown similar results among older adults with increasing frailty [27, 29].

Wan et al. studied 200 community-dwelling elderly with orofacial pain [30]. They reported that $10.5 \%$ of the community-dwelling elderly could not remember the onset of the pain, comparable to $10.1 \%$ of the elderly reporting oral pain in our study who could not remember their oral complaint. This consistent result might be due to an age-related mild memory loss. This means that selfassessment questionnaires given to the elderly should be interpreted with caution because the answers could be biased. Questions on more recent events (e.g., a few weeks in the past) might reduce the risk of such a bias.

This study has shown that $75 \%$ of the elderly who live independently at home and feel the need to receive dental care are able to visit the dentist in the Netherlands. Almost $70 \%$ of them were still able to visit the dentist independently. The study of Skaar and O'Conner in the US showed that only $46 \%$ of community-dwelling elderly yearly visited the dentist [13]. These differences in dental care use may be explained by the fact that in the past when these elderly were young, dental care was provided by the healthcare system in the Netherlands and these elderly are used to regularly visit the dentist. Next, the elderly in our study were suffering from oral pain, which resulted understandably in a higher need for dental treatment and therefore resulted in higher dental care use. 
Table 2 First semi-structured interview

\begin{tabular}{|c|c|c|c|c|c|}
\hline First interview $(n, \%)$ & $\begin{array}{l}\text { Total } \\
(n=89)\end{array}$ & $\begin{array}{l}\text { Robust } \\
(n=54)\end{array}$ & $\begin{array}{l}\text { Frail } \\
(n=9)\end{array}$ & $\begin{array}{l}\text { Complex } \\
(n=26) \\
\end{array}$ & $P$-value between groups \\
\hline Experiencing oral pain at time of interview & $29(32.6 \%)$ & $16(29.6 \%)$ & $2(22.2 \%)$ & $11(42.3 \%)$ & 0.412 \\
\hline $\begin{array}{l}\text { Oral pain lasted } \\
>6 \text { weeks }\end{array}$ & $34(38.2 \%)$ & $19(35.2 \%)$ & $3(33.3 \%)$ & $12(46.2 \%)$ & 0.631 \\
\hline VAS $^{1}$ pain score (mean, SD) & $5.8(2.1)$ & $6.1(2.5)$ & $6.0(1.4)$ & $5.5(1.9)$ & 0.855 \\
\hline No pain complaint or cannot remember & $9(10.1 \%)$ & $5(9.3 \%)$ & $1(11.1 \%)$ & $3(11.5 \%)$ & 0.881 \\
\hline \multicolumn{6}{|l|}{ Measures taken to relieve oral pain complaints } \\
\hline Visited the dentist for oral pain complaint & $50(56.2 \%)$ & $35(64.8 \%)$ & $3(33.3 \%)$ & $12(46.2 \%)$ & 0.100 \\
\hline Other measures (painkillers, mouth rinse) & $9(10.1 \%)$ & $6(11.1 \%)$ & $1(11.1 \%)$ & $2(7.7 \%)$ & 1.000 \\
\hline \multicolumn{6}{|l|}{ Type of oral pain complaint } \\
\hline Toothache & $21(23.6 \%)$ & $15(27.8 \%)$ & $2(22.2 \%)$ & $4(15.4 \%)$ & 0.471 \\
\hline Denture-related complaint & $22(24.7 \%)$ & $10(18.5 \%)$ & $3(33.3 \%)$ & $9(34.6 \%)$ & 0.241 \\
\hline Minor dental complaint & $21(23.6 \%)$ & $12(22.2 \%)$ & $2(22.2 \%)$ & $7(26.9 \%)$ & 0.893 \\
\hline Complicated pain complaints & $6(6.7 \%)$ & $6(11.1 \%)$ & - & $1(3.8 \%)$ & 0.212 \\
\hline Periodontal disease (increased tooth mobility) & $4(4.5 \%)$ & $3(5.6 \%)$ & $1(11.1 \%)$ & $1(3.8 \%)$ & 1.000 \\
\hline Peri-implant pain (peri-implant tissue) & $4(4.5 \%)$ & $2(3.7 \%)$ & - & $1(3.8 \%)$ & 0.545 \\
\hline Fractured teeth, radix relicta & $2(2.2 \%)$ & $1(1.9 \%)$ & - & $1(3.8 \%)$ & 0.635 \\
\hline \multicolumn{6}{|l|}{ Location of the oral pain compliant } \\
\hline Upper jaw & $21(23.6 \%)$ & $13(24.1 \%)$ & $2(22.2 \%)$ & $6(23.1 \%)$ & 0.990 \\
\hline Lower jaw & $39(43.8 \%)$ & $23(42.6 \%)$ & $6(66.7 \%)$ & $10(38.5 \%)$ & 0.326 \\
\hline Both jaws & $10(11.2 \%)$ & $7(13.0 \%)$ & - & $3(11.5 \%)$ & 0.779 \\
\hline Soft tissues & $8(9.0 \%)$ & $5(9.3 \%)$ & - & $3(11.5 \%)$ & 0.750 \\
\hline Not an oral complaint: jaw joint or skin & $2(2.2 \%)$ & $1(1.9 \%)$ & & $1(3.8 \%)$ & 0.635 \\
\hline \multicolumn{6}{|l|}{ Dental visits } \\
\hline Registered with local dentist & $76(85.4 \%)$ & $47(87.0 \%)$ & $7(77.8 \%)$ & $22(84.6 \%)$ & 0.668 \\
\hline Recent dental visit ( $<1$ year) & $67(75.3 \%)$ & $42(77.8 \%)$ & $5(55.6 \%)$ & $20(76.9 \%)$ & 0.350 \\
\hline \multicolumn{6}{|l|}{ Transport to local dentist } \\
\hline Able to visit local dentist independently & $63(70.8 \%)$ & $47(87.0 \%)^{a, b}$ & $4(44.4 \%)$ & $12(46.2 \%)$ & $<0.001$ \\
\hline Uses local services & $11(12.4 \%)$ & $4(7.4 \%)^{b}$ & - & $7(26.9 \%)$ & 0.045 \\
\hline Requires assistance from family or caregiver & $15(16.9 \%)$ & $3(5.6 \%)^{a, b}$ & $5(55.6 \%)$ & $7(26.9 \%)$ & $<0.001$ \\
\hline \multicolumn{6}{|l|}{ Elderly experiencing oral pain during the first interview } \\
\hline Advised local dentist & $19(21.4 \%)$ & $10(18.5 \%)$ & $1(11.1 \%)$ & $8(30.8 \%)$ & 0.334 \\
\hline Requires specialist care & $2(2.2 \%)$ & $1(1.9 \%)$ & $1(11.1 \%)$ & - & 0.276 \\
\hline Receives specialist care & $3(3.4 \%)$ & $3(5.6 \%)$ & - & - & 0.672 \\
\hline Recent or upcoming dental appointment or no appointment needed & $5(5.6 \%)$ & $2(3.7 \%)$ & - & $3(11.5 \%)$ & 0.367 \\
\hline
\end{tabular}

${ }^{1}$ VAS Visual analogue scale

a Statistically significant difference $(p<0.05)$ between robust and frail elderly

b Statistically significant difference $(p<0.05)$ between robust and complex elderly

During the second interview, some elderly indicated that they had not visited the dentist or maxillofacial surgeon. The reason for not visiting the dentist or specialist was that elderly felt no need at the moment and had other problems (usually health problems) that required more attention. Similar conclusions were reached in the study of Gaszynska et al. [31] involving care home residents. Elderly who did not visit the dentist within the last 12 months reported that they experienced problems with accessibility, had other major health problems or felt no need to visit the dentist. Their study population lived in a residential care home, which may have affected the high number of elderly reporting difficulties visiting the dentist. Because these elderly did not live independently at home, they required more help with transportation to visit the dental office. This is in contrast to our 
Table 3 Second semi-structured interview

\begin{tabular}{|c|c|c|c|c|c|}
\hline Second interview $(n, \%)$ & $\begin{array}{l}\text { Total } \\
(n=19)\end{array}$ & $\begin{array}{l}\text { Robust } \\
(n=10)\end{array}$ & $\begin{array}{l}\text { Frail } \\
(n=1)\end{array}$ & $\begin{array}{l}\text { Complex } \\
(n=8)\end{array}$ & $P$-value between groups \\
\hline Still experiencing pain & $15(78.9 \%)$ & $10(100 \%)$ & $1(100 \%)$ & $4(50 \%)$ & 0.033 \\
\hline VAS $^{\mathrm{a}}$ pain (mean, SD) & $4.9(1.8)$ & $4.8(2.0)$ & 2 & $5(1.6)$ & 0.391 \\
\hline Visited a dentist or has an appointment & $15(78.9 \%)$ & $7(70 \%)$ & $1(100 \%)$ & $7(87.5 \%)$ & 0.675 \\
\hline \multicolumn{6}{|l|}{ Transport to local dentist } \\
\hline Able to visit local dentist independently & $7(36.8 \%)$ & $2(20.0 \%)$ & - & $5(62.5 \%)$ & 0.303 \\
\hline Uses local services for transport & $1(5.3 \%)$ & - & $1(100 \%)$ & - & 0.091 \\
\hline Required assistance from family or caregiver & $2(10.5 \%)$ & $2(20 \%)$ & - & $1(12.5 \%)$ & 0.636 \\
\hline \multicolumn{6}{|l|}{ Reasons for not visiting the dentist } \\
\hline No urgency, other (health) problems require more attention & $4(21.0 \%)$ & $3(30 \%)$ & - & $1(12.5 \%)$ & 1.000 \\
\hline
\end{tabular}

aAS: visual analogue scale

study population of elderly living independently at home. When our study population grows older and cannot longer live independently at home, they might encounter the same issues with transport to the dentist.

\section{Strengths and limitations}

The strength of this study is the large study population and the focus in this study on oral pain which is thus far hardly described in literature, making this study unique. The limitation is the rather low response rate (45.9\%). These relatively low response rates are commonly seen in elderly research projects [32-34]. It is most likely that the elderly who did not return the questionnaire and did not participate in this study are older, more frail and have higher needs for complex care. It is very likely that these community-dwelling elderly also have more oral health problems, more oral pain complaints and more problems visiting the dentist.

Elderly are facing often many difficulties with their health. It seems that oral health in the elderly population when compared to other big health issues is not a first a priority [35]. Another possible limitation is the use of self-assessment questionnaires and structured interviews to assess oral health. Even though the structured interview was performed by a researcher who was a dentist, no intraoral examination was conducted, which means that the reported symptoms could not be confirmed clinically.

\section{Conclusion}

Dry mouth and oral pain are most reported oral health problems among community-dwelling elderly. Elderly with complex care needs report most oral health problems. In case an elderly seeks dental treatment to alleviate an oral pain complaint, most elderly in this study were able to organize dental care and transport to the dentist. Frail and complex elderly often need assistance from caregivers to visit the dentist.

\section{Clinical significance}

As long as elderly live independently at home and feel a personal need to receive dental care, they are able to manage their dental care. Elderly with complex care needs report more oral health problems. Therefore caretakers should keep in mind that when frailty progresses, visiting the dentist may become more and more difficult and the risk for poor oral health increases.

\section{Abbreviations \\ GFI: Groningen Frailty Indicator; IM-E-SA: Intermed for the Elderly Self- Assessment; GP: General practitioner}

\section{Acknowledgements}

We kindly thank all co-workers from the Embrace Elderly Care Teams for their support in the data collection and C. Frink for language editing.

\section{Additional information}

Unfortunately, our co-author Klaske Wynia passed away during the process of this study. We are thankful for all the help and inspiration she contributed to the research group.

\section{Ethics and consent to participate}

The Medical Ethical Committee of the University Medical Center Groningen (the Netherlands) approved the Embrace study proposal (reference METc2011.108). Regarding the present study, they concluded that additional approval for assessing perceived oral health and the need for treatment was not required. The study was performed in accordance with the principles expressed in the Declaration of Helsinki. All eligible elderly gave written informed consent when they were asked to participate in the program of Embrace. Verbal informed consent was obtained when elderly were interviewed by telephone regarding their oral pain and access to dental care.

\section{Authors' contributions}

MHB carried out data analysis, drafting article and statistics. SLWS and KW were involved in data collection and study design. AnV and ArV were involved in concept and design, drafting article. SLWS, KW, AnV and ArV were all involved in critical revision of the article. All authors (except for KW who passed away during the writing process) read and approved the final manuscript.

\section{Funding}

No funding was obtained for this study.

\section{Availability of data and materials}

The datasets generated and/or analyzed during the current study are not publicly available due to the fact that the data contains personal information and comments, which are necessary for correct interpretation of oral pain 
complaint. Datasets are available from the corresponding author on reasonable request.

\section{Consent for publication}

Not applicable.

\section{Competing interests}

The authors declare that they have no conflict of interest.

\section{Author details}

'Department of Maxillofacial Surgery, University of Groningen, University Medical Center Groningen, PO Box 30.001, NL-9700, RB, Groningen, The Netherlands. ${ }^{2}$ Department of Health Sciences, Community and Occupational Medicine, University Medical Center Groningen, University of Groningen, Groningen, the Netherlands. ${ }^{3}$ Department of Geriatric Dentistry, Dental School, Center for Dentistry and Oral Hygiene, University of Groningen, University Medical Center Groningen, Groningen, the Netherlands.

Received: 3 January 2020 Accepted: 25 June 2020

Published online: 02 July 2020

\section{References}

1. WHO (World Health Organization). Global health and aging. http://www who.int/ageing/publications/global_health.pdf. Accessed 21 June 2019.

2. United Nations, Department of Economic and Social Affairs, Population Division. World population ageing 2017 - highlights; 2017. http://www.un. org/en/development/desa/population/publications/pdf/ageing/WPA2017 Highlights.pdf. Accessed 21 June 2019.

3. Clegg A, Young J, lliffe S, Olde Rikkert M, Rockwood K. Frailty in elderly people. Lancet. 2013;381(9868):752-62. https://doi.org/10.1016/S01406736(12)62167-9.

4. Lim LM, McStea M, Chung WW, Azmi NN, Aziz SAA, Alwi S, et al. Prevalence, risk factors and health outcomes associated with polypharmacy among urban community-dwelling older adults in multi-ethnic Malaysia. PLoS One. 2017;12:e0173466. https://doi.org/10.1371/journal.pone.0173466.

5. Morin L, Johnell K, Laroche ML, Fastbom J, Wastesson JWL. The epidemiology of polypharmacy in older adults: register-based prospective cohort study. Clin Epidemiol. 2018;10:289-98. https://doi.org/10.2147/CLEP. S153458.

6. Peters $L L$, Boter $H$, Slaets JP, Buskens E. Development and measurement properties of the self assessment version of the INTERMED for the elderly to assess case complexity. J Psychosom Res. 2013;74(6):518-22. https://doi.org/ 10.1016/j.jpsychores.2013.02.003.

7. Müller F, Naharro M, Carlsson GE. What are the prevalence and incidence of tooth loss in the adult and elderly population in Europe? Clin Oral Implants Res. 2007;18(Suppl.3):2-14.

8. Janssens B, Vanobbergen J, Petrovic M, Jacquet W, Schols JMGA, De Visschere $L$. The oral health condition and treatment needs assessment of nursing home residents in Flanders (Belgium). Community Dent Health. 2017:34(3):143-51. https://doi.org/10.1922/CDH_4086Janssens09.

9. Visser A, de Baat C, Hoeksema AR, Vissink A. Oral implants in dependent elderly: a blessing of burden? Gerodontology. 2011;28(1):76-80. https://doi. org/10.1111/j.1741-2358.2009.00314.X.

10. Delwel S, Scherder EJA, de Baat C, Binnekade TT, van der Wouden JC, Hertogh CMPM, et al. Orofacial pain and its potential oral causes in older people with mild cognitive impairment or dementia. J Oral Rehabil. 2019; 46(1):23-32. https://doi.org/10.1111/joor.12724.

11. Masood M, Newton T, Bakri NN, Khalid T, Masood Y. The relationship between oral health and oral health related quality of life among elderly people in the United Kingdom. J Dent. 2017;56:78-83. https://doi.org/10. 1016/j.jdent.2016.11.002.

12. Donnelly LR, Clarke LH, Phinney A, MacEntee Ml. The impact of oral health on body image and social interactions among elderly in long-term care. Gerodontology. 2016:33:480-9. https://doi.org/10.1111/ger.12187.

13. Skaar DD, O'Connor H. Dental service trends for older US adults, 1998-2006. Spec Care Dentist. 2012;32(2):42-8. https://doi.org/10.1111/j.1754-4505.2012. 00239.x.

14. Gerritsen PFM, Cune MS, van der Bilt A, De Putter C. Dental treatment needs in Dutch nursing homes offering integrated dental care. Spec Care Dentist. 2011;31(3):95-101. https://doi.org/10.1111/j.1754-4505.2011.00185.x.
15. Hoeksema AR, Peters LL, Raghoebar GM, Meijer HJA, Vissink A, Visser A. Oral health status and need for oral care of care-dependent indwelling elderly : from admission to death. Clin Oral Investig. 2017;21(7):2189-96. https://doi. org/10.1007/s00784-016-2011-0.

16. Gil-Montoya JA, Ferreira de Mello AL, Barrios R, Gonzalez-Moles MA, Bravo $M$. Oral health in the elderly patient and its impact on general well-being: a nonsystematic review. Clin Interv Aging. 2015;10:461-7. https://doi.org/10. 2147/CIA.S54630.

17. Gluzman R, Meeker H, Agarwal P, Patel S, Gluck G, Espinoza L, et al. Oral health status and needs of homebound elderly in an urban home-based primary care service. Spec Care Dentist. 2013;33(5):218-26. https://doi.org/ 10.1111/j.1754-4505.2012.00316.x.

18. Huppertz VAL, Van der Putten GJ, Halfens RJG, Schols JMGA, De Groot LCPGM. Association between malnutrition and oral health in Dutch nursing home residents: results of the LPZ study. J Am Med Dir Assoc. 2017;18(11): 948-54. https://doi.org/10.1016/j.jamda.2017.05.022.

19. Hoeksema AR, Spoorenberg SLW, Peters LL, Meijer HJA, Raghoebar GM, Vissink $A$, et al. Elderly with remaining teeth report less frailty and better quality of life than edentulous elderly: a cross-sectional study. Oral Dis. 2017; 23(4):526-36. https://doi.org/10.1111/odi.12644.

20. Spoorenberg SL, Uittenbroek RJ, Middel B, Kremer BP, Reijneveld SA, Wynia K. Embrace, a model for integrated elderly care: study protocol of a randomized controlled trial on the effectiveness regarding patient outcomes, service use, costs, and quality of care. BMC Geriatr. 2013;13:62. https://doi.org/10.1186/1471-2318-13-62.

21. Spoorenberg SL, Wynia K, Fokkens AS, Slotman K, Kremer HP, Reijneveld SA. Experiences of community-living older adults receiving integrated care based on the chronic care model: a qualitative study. PLoS One. 2015; 10(10):e0137803. https://doi.org/10.1371/journal.pone.0137803.

22. Uittenbroek RJ, Reijneveld SA, Stewart RE, Spoorenberg SL, Kremer HP, Wynia K. Development and psychometric evaluation of a measure to evaluate the quality of integrated care: the patient assessment of integrated elderly care. Health Expect. 2016;19(4):962-72. https://doi.org/10.1111/hex. 12391.

23. Uittenbroek RJ, Kremer HPH, Spoorenberg SLW, Reijneveld SA, Wynia K. Integrated care for older adults improves perceived quality of care: results of a randomized controlled trial of embrace. J Gen Intern Med. 2017;32(5): 516-23. https://doi.org/10.1007/s11606-016-3742-y.

24. Peters LL, Boter H, Buskens E, Slaets JP. Measurement properties of the Groningen frailty indicator in home-dwelling and institutionalized elderly people. J Am Med Dir Assoc. 2012;13(6):546-51. https://doi.org/10.1016/j. jamda.2012.04.007.

25. Deveraj CG, Eswar P. Reasons for use and non-use of dental services among people visiting a dental college hospital in India: a descriptive crosssectional study. Eur J Dent. 2012;6(4):422-7.

26. Kikwilu EN, Masalu JR, Kahabuka FK, Senkoro AR. Prevalence of oral pain and barriers to use of emergency oral care facilities among adult Tanzanians. BMC Oral Health. 2008;8:28. https://doi.org/10.1186/1472-6831-8-28.

27. Kamdem B, Seematter-Bagnoud L, Botrugno F, Santos-Eggimann B. Relationship between oral health and Fried's frailty criteria in communitydwelling older persons. BMC Geriatr. 2017;17(1):174-017-0568-3. https://doi. org/10.1186/s12877-017-0568-3.

28. Bakker MH, Vissink A, Spoorenberg SLW, Jager-Wittenaar $H$, Wynia K, Visser A. Are edentulousness, oral health problems and poor health-related quality of life associated with malnutrition in community-dwelling elderly (ages 75 years and over)? A cross-sectional study. Nutrients. 2018;10(12):E1965. https://doi.org/10.3390/nu10121965.

29. Watanabe $Y$, Hirano H, Arai H, Morishita S, Ohara Y, Edahiro A, et al. Relationship between frailty and oral function in community-dwelling elderly adults. J Am Geriatr Soc. 2017;65(1):66-76. https://doi.org/10.1111/ jgs. 14355 .

30. Wan KY, McMillan AS, Wong MC. Orofacial pain symptoms and associated disability and psychosocial impact in community-dwelling and institutionalized elderly in Hong Kong. Community Dent Health. 2012;29(1):110-6.

31. Gaszynska E, Szatko F, Godola M, Gaszynski T. Oral health status, dental treatment needs, and barriers to dental care of elderly care home residents in Lodz, Poland. Clin Interv Aging. 2014;9:1637-44. https://doi.org/10.2147/ CIA.S69790.

32. Habicht DW, Witham MD, McMurdo MET. The underrepresentation of older people in clinical trials: barriers and potential solutions. J Nutr Health Aging. 2008;12(3):194-6. https://doi.org/10.1007/BF02982619. 
33. Edelman LS, Yang R, Guymon M, Olson LM. Survey methods and response rates among rural community dwelling older adults. Nurs Res. 2013;62(4): 286-91. https://doi.org/10.1097/NNR.0b013e3182987b32.

34. Vettore MV, Faerstein E, Baker SR. Social position, social ties and adult's oral health: 13 year cohort study. J Dent. 2016;44:50-6. https://doi.org/10.1016/j. jdent.2015.12.004.

35. Niesten $D$, van Mourik $K$, van der Sanden $W$. The impact of frailty on oral care behavior of older people: a qualitative study. BMC Oral Health. 2013;13: 61. https://doi.org/10.1186/1472-6831-13-61.

\section{Publisher's Note}

Springer Nature remains neutral with regard to jurisdictional claims in published maps and institutional affiliations.

Ready to submit your research? Choose BMC and benefit from:

- fast, convenient online submission

- thorough peer review by experienced researchers in your field

- rapid publication on acceptance

- support for research data, including large and complex data types

- gold Open Access which fosters wider collaboration and increased citations

- maximum visibility for your research: over $100 \mathrm{M}$ website views per year

At $\mathrm{BMC}$, research is always in progress.

Learn more biomedcentral.com/submissions 